\title{
Do cancer drugs improve survival or quality of life?
}

\author{
@ @ $\mathbb{Q} \Theta$ OPEN ACCESS \\ You don't need to know, according to our broken regulatory system
}

\author{
Vinay Prasad assistant professor of medicine \\ Oregon Health and Science University, Portland, Oregon, USA
}

\begin{abstract}
When in the lifecycle of a cancer drug should an improvement in survival or quality of life be demonstrated? Some people argue that these benefits should be clearly evident before marketing. Others, me included, believe that for some indications, including terminal cancers with few treatment options, a drug might receive provisional approval based on surrogate outcomes (such as tumour shrinkage or progression-free survival), with overall survival or quality of life assessed after market authorisation. Although there is no consensus, the one answer that seems absolutely unjustifiable is never. And yet, this is often what happens, according to two recent studies.
\end{abstract}

The first found that between 2008 and 2012 the US Food and Drug Administration approved most uses of cancer drugs without evidence of survival or improved quality of life (67\%, $36 / 54) .{ }^{1}$ Among the 36 such approvals, only five (14\%) uses were shown later to improve survival compared with existing treatments or placebo after a median of 4.4 years on the market. The linked paper by Davis and colleagues (doi:10.1136/bmj. j4530) extends these findings. ${ }^{2}$ In their study of cancer drugs approved by the European Medicines Agency between 2009 and $2013,57 \%$ (39/68) had no supporting evidence of better survival or quality of life when they entered the market. After a median of 5.9 years on the market, just six of these $39(15 \%)$ agents had been shown to improve survival or quality of life.

\section{Minimal benefit}

Three further facts help characterise the current regulatory climate. Firstly, when drugs do offer survival advantages, the gains are often marginal. Fojo and colleagues found that the median improvement in survival among patients treated with 71 drugs for solid tumours was just 2.1 months. ${ }^{3}$ Davis and colleagues agree. Of the 23 drugs that improved survival, 11 (48\%) failed to meet the modest definition of "clinically meaningful benefit" set by the European Society of Medical Oncology.

All three aforementioned analyses ${ }^{1-3}$ consider only measured improvements in survival and not mathematically derived or modelled estimates. This is for good reason. Modelled estimates make assumptions to predict survival benefits that might occur during longer follow-up or adjusting for differences in post-study treatment between groups. Modelled estimates are uncertain and seem to be consistently larger than measured gains, ${ }^{4}$ raising question about their fidelity.

Secondly, the small benefits of cancer drugs typically occur in trials conducted in unrepresentative patient populations-patients who are younger and with less comorbidity than average clinical populations. ${ }^{5}$ When a marginal drug advantage is applied to a real world population, a small benefit may vanish entirely because of the fine balance between risks and benefits typical of these agents. ${ }^{5}$

Finally, many of the surrogate outcomes used for drug approval are poorly correlated with survival. ${ }^{6}$ For others, the strength of the correlation is untested. ${ }^{7}$ This is true for the FDA's regular approval pathway as well as the accelerated approval route. ${ }^{6}$ Notably, regular approvals are not usually coupled to postmarketing requirements for further trials to confirm effectiveness and safety. This means that the surrogate outcome, often unvalidated, may be all we ever have.

\section{Better patient value}

Taken together, these facts paint a sobering picture. Although we are approving cancer drugs at a rapid pace, few come to market with good evidence that they improve patient centred outcomes. If they do, they often offer marginal benefits that may be lost in the heterogeneous patients of the real world. Most approvals of cancer drugs are based on flimsy or untested surrogate endpoints, and postmarketing studies rarely validate the efficacy and safety of these drugs on patient centred endpoints. Add to this that the average cancer drug costs in excess of $\$ 100000$ ( $£ 75000$; $€ 85000$ ) per year of treatment, and the conclusion seems that the regulatory system is broken.

In the US, this broken system means huge expenditures on cancer drugs with certain toxicity but uncertain benefit. The US Medicare programme is legally required to pay for any drug approved by the FDA without negotiation on price. 
In Europe, agencies such as the National Institute for Health and Care Excellence (NICE) exclude from reimbursement drugs that provide only marginal or uncertain benefits at high cost. ${ }^{8}$ Their decisions are continually subjected to political scrutiny and public criticism. However, it is only because regulators are lax that payers have had to wield the stick.

What can be done? The default path to market for all cancer drugs should include rigorous testing against the best standard of care in randomised trials powered to rule in or rule out a clinically meaningful difference in patient centred outcomes in a representative population. The use of uncontrolled study designs or surrogate endpoints should be the exception not the rule. When surrogates are used, postmarketing studies with clinically meaningful and patient centred outcomes must be started, completed, and published. Patient level data should be shared. Health technology assessment programmes should reject modelled measurements of survival, which may unintentionally incentivise the industry not to conduct trials that evaluate survival directly and rely instead on modelling.

The expense and toxicity of cancer drugs means we have an obligation to expose patients to treatment only when they can reasonably expect an improvement in survival or quality of life. The study by Davis and colleagues suggests we may be falling far short of this important benchmark.

Competing interests: I have read and understood BMJ policy on declaration of interests and declare royalties from my book Ending Medical Reversal.
Provenance and peer review: Commissioned; not externally peer reviewed.

$1 \quad$ Kim C, Prasad V. Cancer drugs approved on the basis of a surrogate end point and subsequent overall survival: An analysis of 5 years of US Food and Drug Administration approvals. JAMA Intern Med 2015;359:1992-4. doi:10.1001/jamainternmed.2015. 5868 pmid:26502403.

2 Davis $\mathrm{C}, \mathrm{Naci} \mathrm{H}$, Gurpinar E, et al. Availability of evidence on overall survival and quality of life benefits of cancer drugs approved by the European Medicines Agency: retrospective cohort study of drug approvals from 2009-2013. BMJ 2017;359:j4530.

3 Fojo T, Mailankody S, Lo A. Unintended consequences of expensive cancer therapeutics - the pursuit of marginal indications and a me-too mentality that stifles innovation and creativity: the John Conley Lecture. JAMA Otolaryngol Head Neck Surg 2014;359:1225-36. doi:10.1001/jamaoto.2014.1570 pmid:25068501.

4 Prasad V. Overestimating the benefit of cancer drugs. JAMA Oncol 2017. doi:10.1001/ jamaoncol.2017.0107 pmid:28715568.

5 Sanoff HK, Chang Y, Lund JL, O'Neil BH, Dusetzina SB. Sorafenib effectiveness in advanced hepatocellular carcinoma. Oncologist 2016;359:1113-20. doi:10.1634/ theoncologist.2015-0478 pmid:27185615.

$6 \mathrm{Kim}$ C, Prasad V. Strength of validation for surrogate end points used in the US Food and Drug Administration's approval of oncology drugs. Mayo Clin Proc 2016;359:713-25. doi: 10.1016/j.mayocp.2016.02.012 pmid:27236424.

7 Kantarjian H, Rajkumar SV. Why are cancer drugs so expensive in the United States, and what are the solutions?Mayo Clin Proc 2015;359:500-4. doi:10.1016/j.mayocp.2015. 01.014. pmid:25792242.

8 Cohen D. Most drugs paid for by £1.27bn Cancer Drugs Fund had no "meaningful benefit."BMJ 2017;359:j2097. doi:10.1136/bmj.j2097 pmid:28455308.

Published by the BMJ Publishing Group Limited. For permission to use (where not already granted under a licence) please go to http://group.bmj.com/group/rights-licensing/ permissions

This is an Open Access article distributed in accordance with the Creative Commons Attribution Non Commercial (CC BY-NC 4.0) license, which permits others to distribute, remix, adapt, build upon this work non-commercially, and license their derivative works on different terms, provided the original work is properly cited and the use is non-commercial. See: http://creativecommons.org/licenses/by-nc/4.0/. 